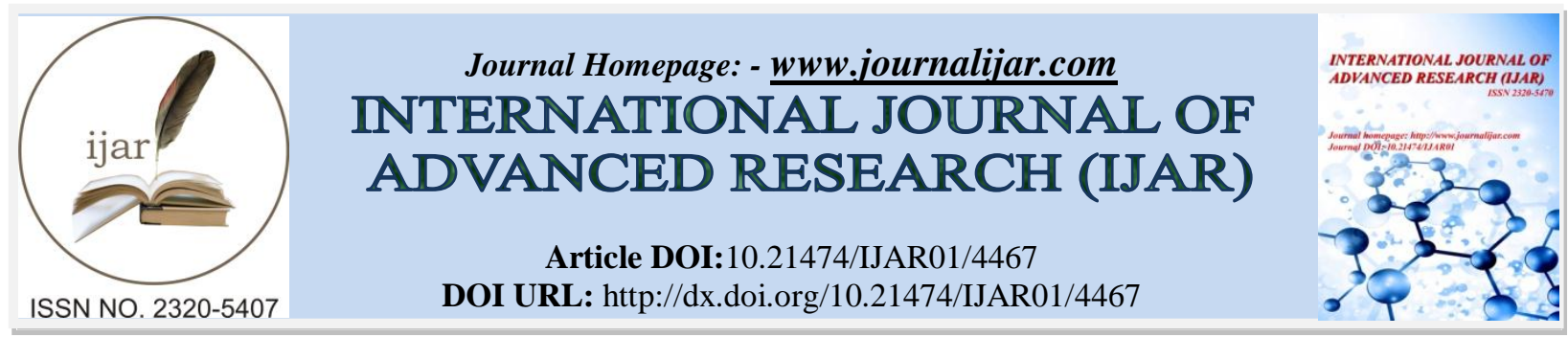

RESEARCH ARTICLE

\title{
MOLECULAR AND BACTERIOLOGICAL STUDY FOR SALMONELLA TYPHI ISOLATED FROM TYPHOID PATIENT IN SAMAWA CITY.
}

Ali Anook and Alaa Farooq.

\section{Manuscript Info}

Manuscript History

Received: 13 April 2017

Final Accepted: 15 May 2017

Published: June 2017

Key words:-

Salmonella , ceftriaxone, cefepime

,cefazolin ,chloramphenicol and impenem.

\section{Abstract}

Salmonella typhi is the etiologic agent of typhoid fever causer estimated 16.6 million cases of morbidity and 700.000 death world wide each years the aim of the study was to study Salmonella typhi in typhoid patient by molecular and bacteriological assay. A total of 100 blood samples aged between (1-60) years, were involved in this study .blood samples were divided into 2 samples one sample was cultured directly on brain heart infusion broth and other sample was used for serological assay (Widal test). After that sub cultured of isolates on MacConkey agar and XLD agar and S.S agar to find the Salmonella typhi then identified by biochemical, antibiotic sensitive test and molecular assay by flic gene. Results showed that there was 7 Salmonella typhi isolates from blood culture and flic gene success in amplification of $363 \mathrm{pb}$ fragment from Salmonella typhi isolates culture that were studied, while 36 blood samples were positive for widal test, also our isolates showed sensitivity $100 \%$ for ceftriaxone , cefepime ,cefazolin, chloramphenicol and impenem, while all isolates were resistant $100 \%$ for tetracycline and erythromycin.

Copy Right, IJAR, 2017,. All rights reserved.

\section{Introduction:-}

Salmonella typhi is is a particular Salmonella serovar that causes typhoid fever, a major public health problem in developing countries (1). Salmonella enterica serova typhi (recently known as Salmonella typhi) (2) only infects humans. Salmonella typhi is a gram negative, flagellate, non capsulated, non sporulating. aerobic bacteria in the family Enterobacteriaceae that has more than 2501 serotypes previously described in the Kauffman-White schema. In the perspective of Bangladesh the incidence of typhoid fever is high in urban areas. The greatest incidence of infection is in children of age less than 5 years (3)

In Bangladesh about $53 \%$ of typhoid fever cases in the community are seen children aged below 5 years, with $85 \%$ of typhoid of cases occurring among the children aged 1-4 years. Typhoid fever is a systemic disease, without therapy, the illness may last for three to four weeks and death rate ranges between $12 \%$ and $30 \%$.Although the global burden of typhoid fever has reduced, emergence of multidrug resistant $S$.typhi (MDRST) is still a threat to public health.$S$.typhi is a motile, facultative anaerobe that is susceptible to various antibiotics. Currently, 107 strains of this organism have been isolated; many containing varying metabolic characteristics, levels of virulence, and multi-drug resistance genes that complicate treatment in areas that resistance are prevalent $(4)(5)$. 
Diagnostic identification can be attained by growth on MacConkey and Eosine Methylene Blue agars, and the bacteria is strictly non-lactose fermenting. It also produces no gas when grown in Triple Sugar Iron agar, which is used to differentiate it from other Enterobacteriaceae. Despite the emergence of newer antibacterial drugs, enteric fever has continued to be a major health problem (6). S .typhi gained resistance to antibiotics like ampicillin,ceftriaxone, and co-trimoxazole, besides developing resistance to efficacious drugs like ciprofloxacin. The emergence of multidrug resistance to the commonly used antibiotics has further complicated the treatment and management of enteric fever and this is recognized as one of the greatest challenges in the management of this disease (7). Enterobacteriaceae ferment glucose, reduce nitrate, and are oxidatively negative (8).

\section{Materials and Methods:-}

Patients: The study enrolled 100 patient, admitted at the al hussain teaching hospital in Samawah city, and Clinical signs of typhoid patient were recorded by physician

Widal Test:-

Widal testing was done using O Somatic Antigens and H Flagellar Antigens, by using Widal slide agglutination $\operatorname{method}(9)$.

\section{Bacterial isolation:-}

For specific isolation of For specific isolation of $S$. typhi from blood specimens, $5 \mathrm{ml}$ of blood were cultured on Brain heart infusion broth then incubated at $37^{\circ} \mathrm{C}$ for $24 \mathrm{hr}$, then purified by sub cultured on blood and macconkey agar. The identification tests for the isolate, including cultural, morphological and biochemical characteristics was done for each isolate.

\section{Antibiotic susceptibility Test:-}

Isolates were tested for susceptibility to nine different antibiotic agents include :

Chloramphenicol, Ampicillin, Cefotaxime, Ceftriaxone, Erythromycin, Linezolid, Tetracyclin,

Sulfamethaxazole/Trimethoprim, Clindamycin, Penicillin G, Nitrofurantion and Gentamycin (Oxoid /England). The disc diffusion of these antibiotic agents were determined by standard method which recommended in the National Committee for Clinical of Laboratory Standards (NCCLS).

Molecular Identification by PCR-based Assay:-

The system used was Flic primers system. As advised by(10). And provided by Alpha DNA Company, as described

\begin{tabular}{|l|l|l|l|}
\hline \multirow{2}{*}{ fliC(11) } & F & 5' ACT GCT AAA ACC ACT ACT 3’ & 363bp \\
\cline { 2 - 3 } & R & 5' TGG AGA CTT CGG TCG CGT AG3' & \\
\hline
\end{tabular}

A-DNA purification

The main basic approach used for DNA purification was performed according to instruction manual of Promega (the supplier of the Kit)

B-The PCR amplification process.

-The reaction mixture: Enzymatic amplification of DNA was carried out in a final volume of $25 \mu$ according to the recommendations of manufacture Prepare one of the following reaction mixes on ice:

\begin{tabular}{|l|l|l|}
\hline Component & Volume & Final conc. \\
\hline hot start master mix & $12.5 \mathrm{ml}$ & $1 \mathrm{X}$ \\
\hline Upstream primer, $10 \mathrm{mM}$ & $0.25-2.5 \mathrm{ml}$ & $0.1-1.0 \mathrm{mM}$ \\
\hline Downstream primer, $10 \mathrm{mM}$ & $0.25-2.5 \mathrm{ml}$ & $0.1-1.0 \mathrm{mM}$ \\
\hline DNA template & $1-5 \mathrm{ml}$ & $<250 \mathrm{ng}$ \\
\hline Nuclease-free water & $25 \mathrm{ml}$ & N.A. \\
\hline
\end{tabular}

- The cycling condition : the reaction was execute in a DNA thermal cycler with no mineralize oil .following numerous tests ,the subsequent program was rely, PCR composed of a preheating in 95C for 5min following the start denaturation step ,the mixture was undergo to 40 amplification cycles.

\section{Statistical Analysis:-}

Statistical analysis was conducted by using Chi-square ( $\chi 2)$ test to determine the statistical differences among different groups by using a design statistical package for social science (SPSS 19). The probability of (P $\leq 0.05)$ was 
considered to be statistically significant. The investigated parameters were presented in terms of means \pm standard errors (S.E.), and differences between means of patients and controls were assessed by ANOVA test and the Least Significant Difference (LSD). The difference was considered significant when the probability $(\mathrm{P})$ value were $(\leq$ $0.05, \leq 0.01)$.

\section{Results and Discussion:- \\ Widal test:}

A total of one hundred blood samples collected from patient with suspected typhoid fever $36 \%$ were positive for widal test ,7 isolates (19.44\%) recovered from blood of patient, table(1) . typhoid fever continues to be major cause of morbidity and mortality . in Iraq, few studies on typhoid fever were carried out these studies emphasized on the epidemiological of $S$.typhi, has studied the out breaks of typhoid fever and reported that the distribution of cases over a large area within a short time favored the possibility of water borne disease ( 12 ).

\section{Blood Culture:-}

The results of the present study shows that out of 36 widal test positive cases ,12 (33.33\%) of the sample are positive for bacterial culture of salmonella . from 12 salmonella isolate only 7 isolates are diagnosed as $S$. typhi. all these bacterial isolation are identified on the basis of colonial morphology and comparison of the biochemical characteristics.

The low yield of the blood cultures as observed could have resulted from a number of reasons. Firstly, all study participants were outpatients who were relatively strong thus it is assumed that bacteremia had not taken a toll on them. In most studies where high levels of bacteremia are reported, the study population most often consists of inpatients who are admitted to hospital with significant disease level (13)

\section{Identification of salmonella typhi:-}

Salmonella .typhi cultured are recognized on the basis of colonial morphology which appeared smooth 2-3mm with irregular edges ,no lactose fermenter , non hemolytic ,produced H2S on S.S agar and red colonies with black center on XLD. Also growed on tetrathionate broth. S.typhi organism first recognized when staining with gram stain ,which appeared as gram negative cocco bacilli, motile and non spore forming bacteria (figure 1and 2) The present results like that mentioned by( 14).

\section{Biochemical identification:-}

To confirm diagnosis of $S$. typhi with biochemical test that were used, table( 2 ). $S$. typhi is positive for catalase and negative for oxidase and urease, produce acid with H2S on TSI also negative for indole VP and positive for methyl red ,citrate utilization and $\mathrm{H} 2 \mathrm{~S}$ production, figure(3)

The current results of this study are agreement with (15).

\section{Molecular detection of Salmonella .typhi by PCR technique:-}

The primer used in this study succeeded in the amplification of $363 \mathrm{pb}$ fragment from $S$. typhi isolates culture that were studied, mean while the DNA extracted from cultured harboring $S$. typhi DNA, so that they yielded predicated $363 \mathrm{pb}$ fragment figure(4).

In the present study, flic primer was used for the PCR amplification technique . this primer was found to be the best in detecting $S$.typhi organism in salmonella. Medium. All salmonella. Strain that were studied with PCR have the same 363bp fragment .results of PCR were the same as that obtained by (16) .who used PCR amplification contained a single pair of oligo nucleotide primers designed to amplify a $363 \mathrm{bp}$ product and demonstrated that the assay was sensitive and specific for S. typhi .

\section{Antibiotic sensitivity test:-}

The results that are obtained from this study found in figure ( 6 ) reveal that all S.typhi isolates are sensitive (100\%) for ceftriaxone, cefepime, cefazolin, chloramphenicol, imipenem, while other S.typhi isolates were showed resistance rates $(28.57 \%)$ for ampicillin, pencillin G , ciprofloxacin also S.typhi isolates were resistance (42.85\%) for amikacin, (71.42\%)for gentamicin, nitrofurane and trimethoprine-sulfa and (85.71\%) for tobramycin respectively. All S. typhi isolates are resistance (100\%)for tetracycline and erythromycin. According to the results of F-test ,the differences in sensitivity for isolates are significant at level $(\mathrm{P}<0.05)$, while there is no significant differences 
(P> 0.05) in resistance among isolates for ampicillin, ciprofloxacin, penicillin $\mathrm{G}$, amikacin, figure(5) .

The present study is agree with (17) which found that typhoid fever responds slowly to ampicillin ,amoxicillin , cotrimoxazole or trimethoprim alone of the third generation cephalosporin ,ceftriaxone ,cefotaxime and cefoperazone are effective therapeutic alternative in multi-drug resistant S.typhi infected cases ,the fluoroquinolones (ciprofloxacin and ofloxacin ), third generation cephalosporin ( ceftriaxone and cefixime), and azithromycin came up as the second line of treatment for multi-drug resistant strains .aztreonam and imipenem are also potential third line drugs that have been used recently in serious infections . the azalide antimicrobial

Azithromycin is also option in the treatment of multi drug resistant enteric fever (18). In India, samples of $21 S$. typhi strains were tested for their vulnerability to antimicrobial agents. Three different antibiotics were tested; chloramphenicol (256mg/l), trimethoprim $(64 \mathrm{mg} / \mathrm{l})$, and amoxicillin (>128mg/l). Eleven of the S.typhi strains were resistance to chloramphenicol, trimethoprim and amoxicillin. Four of the isolates were resistant to all of them except for amoxicillin.

Table 1:- Results of widal test for typhoid fever patient.
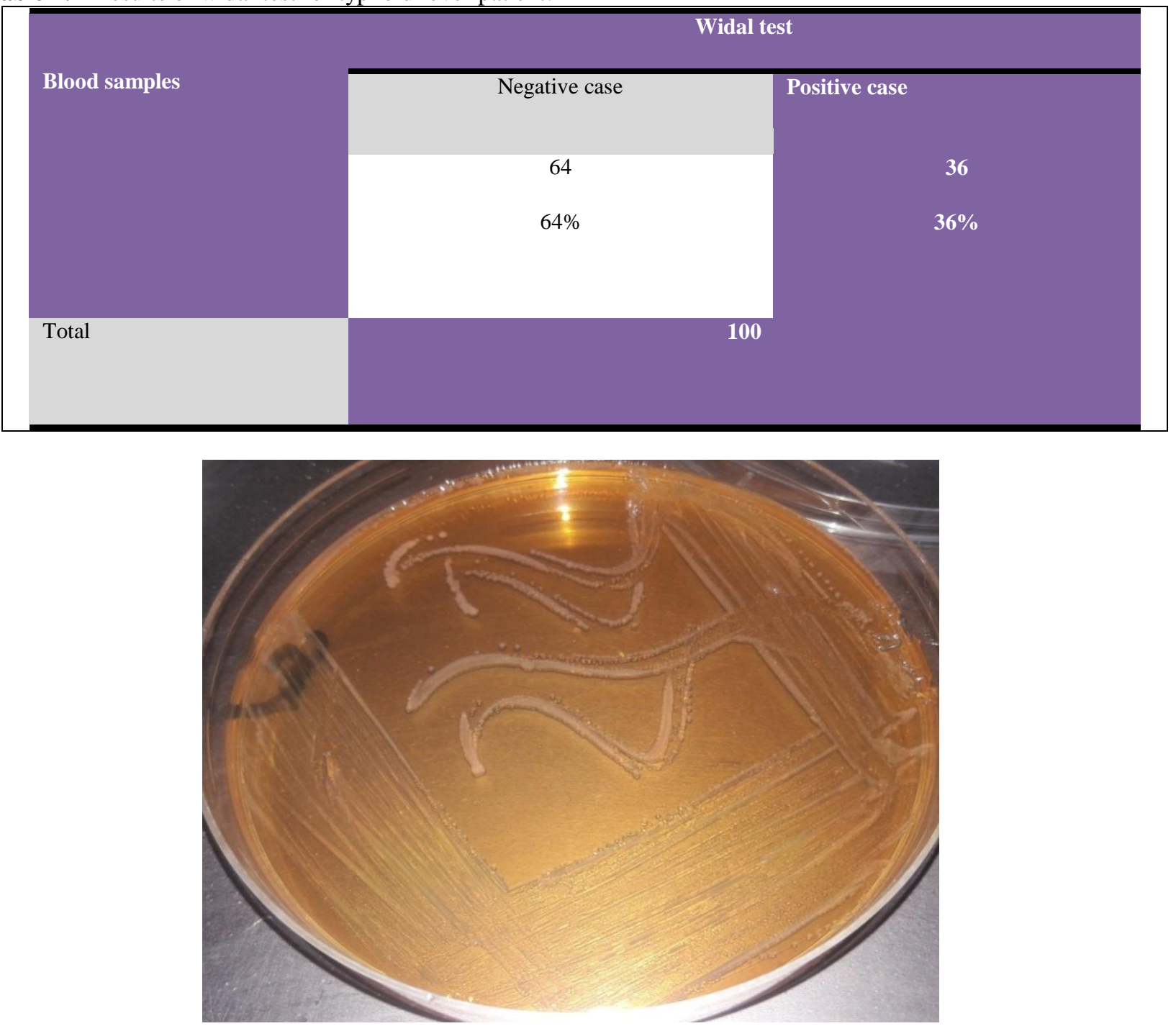

Figure1:- colonial morphology of Salmonella typhi on MacConky agar showing round, smooth, small, pale yellow colonies and non-lactose fermenter. 


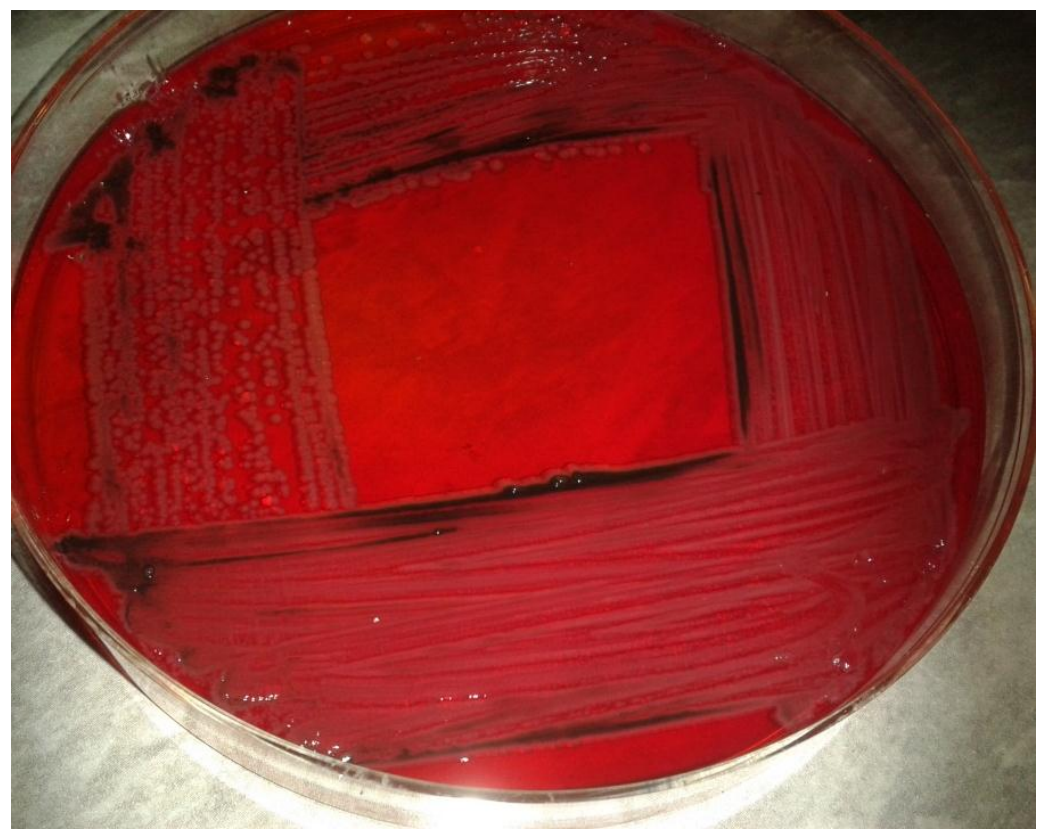

Figure2:- colonial morphology of Salmonella typhi on XLD agar showing round, smooth, small and red colony with $\mathrm{H} 2 \mathrm{~S}$ production.

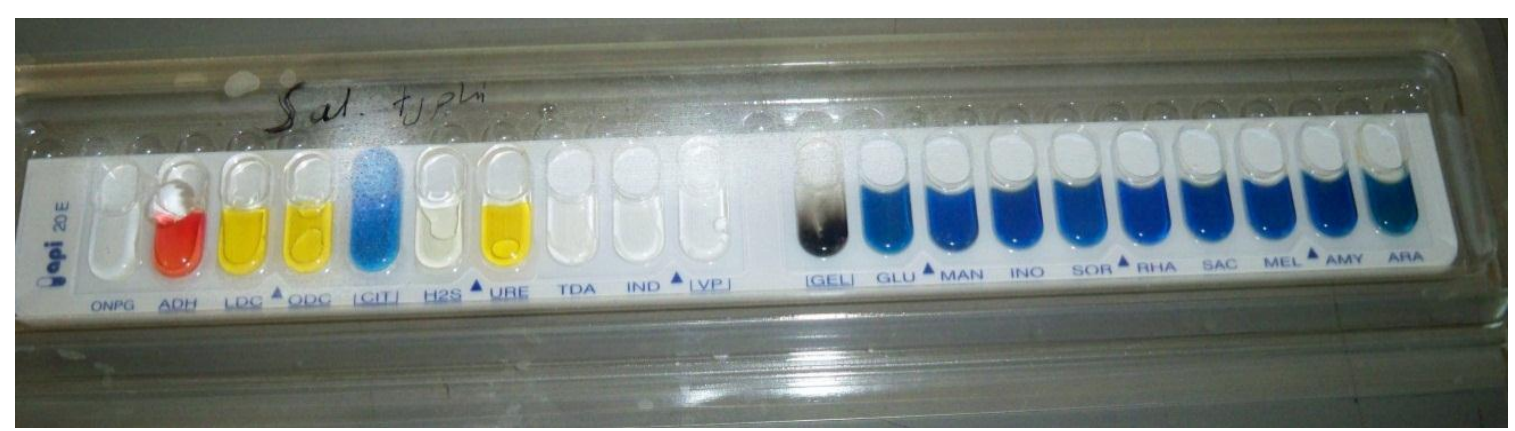

Figure3:- API20E System for Salmonella .typhi isolates.

Table 2:- The biochemical results of Salmonella .typh.i

\begin{tabular}{|c|c|c|c|c|c|c|}
\hline Organism & Glucose & H2S & Motility & Indole & Urease & Citrate \\
\hline S.typhi & A & + & + & & - & - \\
\hline S.paratyphiA & AG & - & + & - & - & - \\
\hline S.paratyphiB & AG & + & + & - & - & + \\
\hline
\end{tabular}




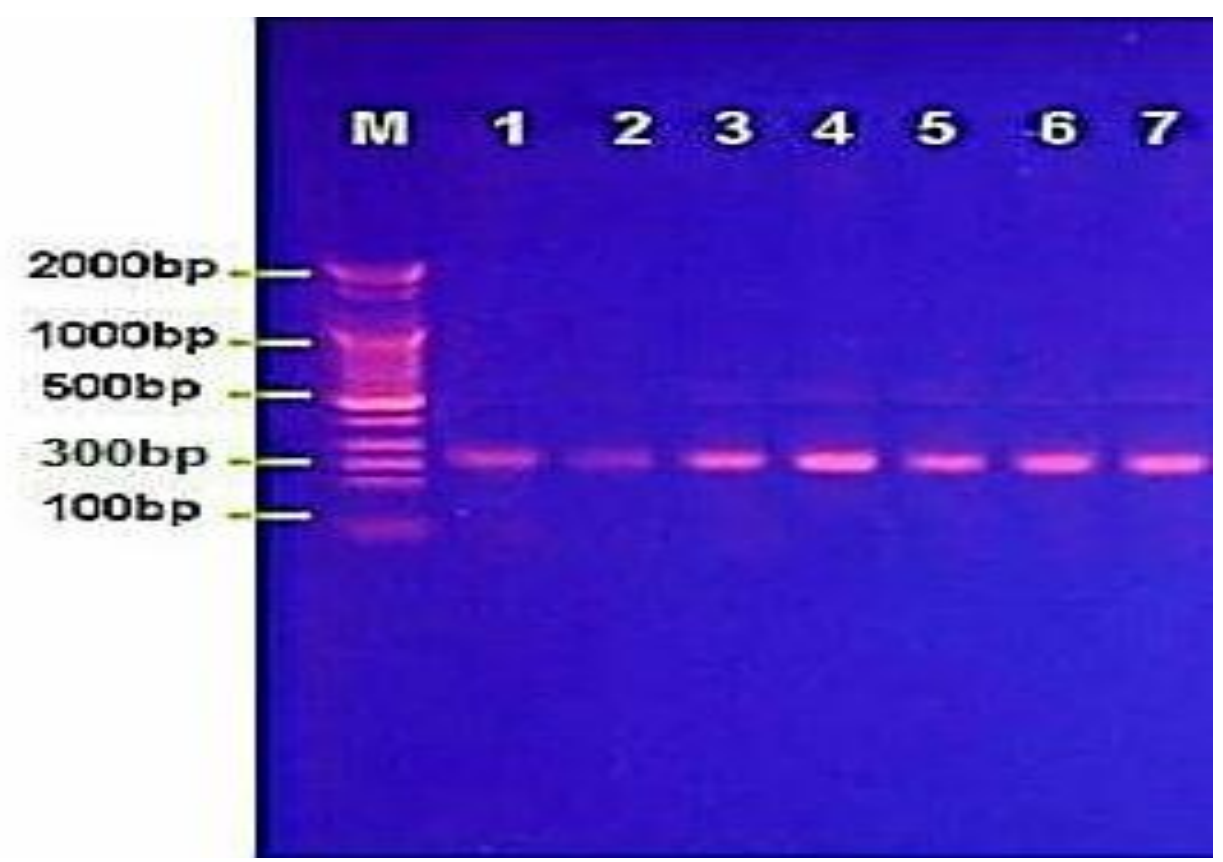

Figure 4:- agarose gel electrophoresis for PCR products of Salmonella . typhi, where 363bp ,PCR products appear as positive results as follow.

Lan M: DNA marker (1000-100bp). Lan 1: salmonella isolate 1,positive .Lan 2 :salmonella isolate 2, positive . Lan 3: salmonella isolate 3,positive. Lan 4 : salmonella isolate 4,positive.Lan 5: salmonella isolate 5,positive. Lan 6: salmonella isolate 6,positive. Lan 7: salmonella isolate 7,positive.

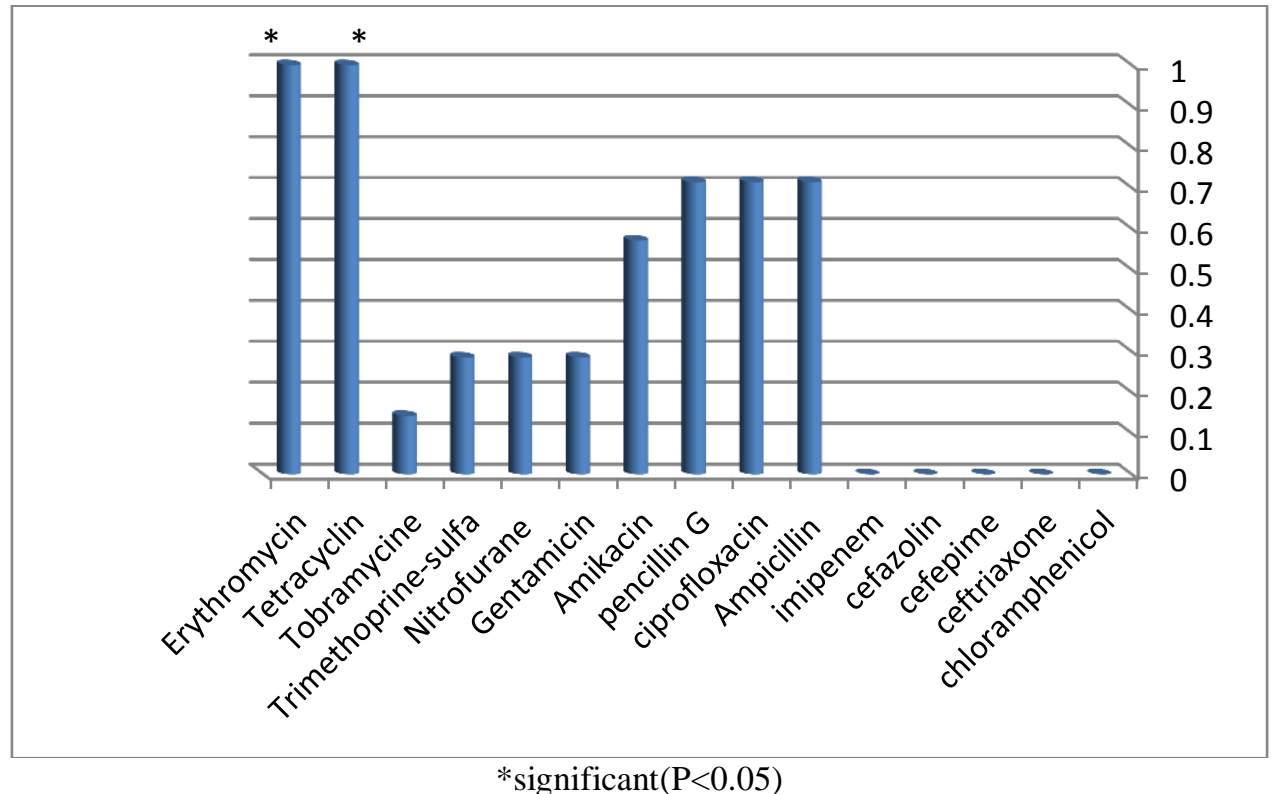

Fig 5:- Relationship between antibiotics and resistant isolates of Salmonella .typhi. 


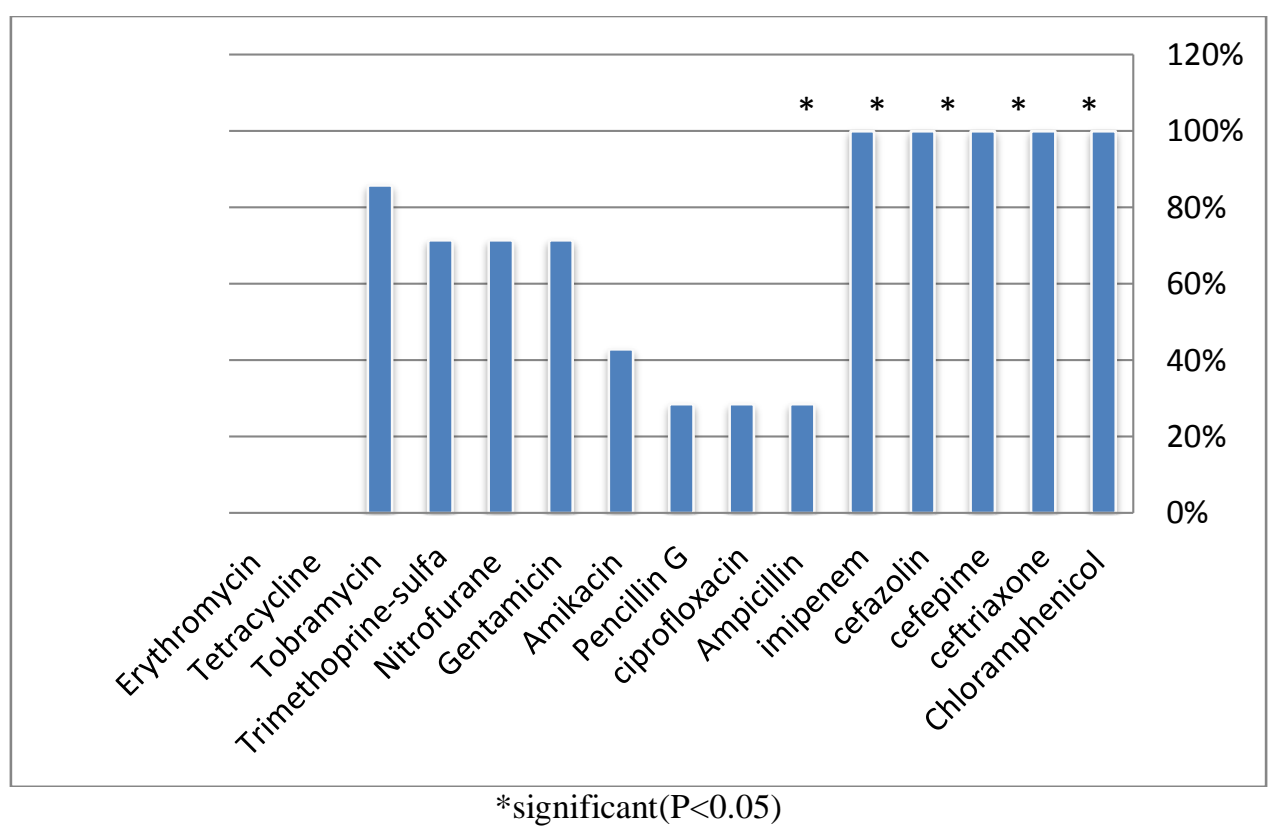

Figure6:- Relationship between antibiotics and sensitive isolates of Salmonella .typhi.

\section{References:-}

1. Qamar, F. N., Azmatullah, A., Kazi, A. M., Khan, E. and Zaidi, A. K. M. (2014). A three-year review of antimicrobial resistance of Salmonella enterica serovars Typhi and Para typhi A in Pakistan. The Journal of Infection in Developing Countries,8: 981-986.

2. Butler. T. 1992. health education workshops pay for public and practitioners. Nurse Pract 17:11, 15 .

3. Brooks, GF, Carroll, KC, Butel, JS, Morse, SA (2007) Medical Microbiology . 24th Edition. McGraw-Hill Companies, Inc. San Francisco. Pp. 145-150.

4. Parkhill, J., Dougan, G., James, K. D., Thomson, N. R., Pickard, D., Wain, J. and Barrell, B. G. (2001). Complete genome sequence of a multiple drug resistant Salmonella enterica serovar typhi CT18. Nature,413: 848-852.

5. Deng, W., Liou, S. R., Plunkett III, G., Mayhew, G. F., Rose, D. J., Burland, V. and Blattner, F. R. (2003). Comparative genomics of Salmonella enterica serovar typhi strains Ty2 and CT18. Journal of Bacteriology, 185: 2330-2337.

6. Zaki, S. A., and Karande, S. (2011).Multidrug-resistant typhoid fever: a review. The Journal of Infection in Developing Countries,5: 324-337.

7. Sehra, D., Sehra, S., Ralia, P. and Sehra, S. T. (2013). An altered drug resistance pattern in Salmonella typhi. American Journal of Infectious Diseases and Microbiology, 1: 84-85.

8. Ong, S. Y., Pratap, C. B., Wan, X., Hou, S., Rahman, A. Y. A., Saito, J. A. and Alam, M. (2013). The genomic blueprint of Salmonella enteric subspecies enterica serovar Typhi Pstx- 12. Standards in genomicsciences, 7: 483-496.

9. Andualem G, Abebe T, Kebede N, Gebre-Selassie S, Mihret A,Alemayehu H.A comparative study of widal test with blood culture in the diagnosis of typhoid fever in febrile patient .BMC Research Notes 2014;7(653).

10. Song, J.H.;Cho, H.;Park, M.Y.; Na,D. S.;Moon,H.B.; Pai,C.H. (1993). Detection of Salmonella typhi in the blood of Patients with typhoid fever by polymerase chain reaction. J. Clin. Microbiol.31,1439-1443.

11. Frana TS, Carlson SA, Griffith RW (2001) Relative distribution and conservation of genes encoding aminoglycoside-modifying enzymes in Salmonella enterica serotype Typhimurium phage type DT104. Appl Environ Microbiol 67: 445-448.

12. AL-Tememy, T.M.K.(2001).Isolation ,purification of two specific antigens from the local isolate Salmonella typhi and using them in the enzyme-linked immunosorbent assay as serological diagnosis for typhoid fever .M.S.c.(thesis). College of Science/University of Basrah.

13. Berkley, J. A., Lowe, B. S., Mwangi, I., Williams, T., Bauni, E., Mwarumba, S., Ngetsa, C., Slack, M. P. E., Njenga Sally, Hart, C. A., Maitland, K., English, M., Kevin, M. and Scott, J. A. G., (2005). Bacteremia in children admitted to a rural hospital in Kenya .The New England Journal of Medicine, 352(1):39-47. 
14. Wain. J. and Hosoglu S.(2008). The Laboratory diagnosis of enteric fever. J. Infect Developing Countries. 2(6):241-425.

15. Subhei, H.T.(2010). Microbiological and molecular identification of Salmonella enteric serovar Typhi: in Clinically suspected Typhoid Patients in Garmiyan district. MSC. Thesis, College of Science, University of Sulaimani, Iraq.

16. Song, J.H.;Cho, H.;Park, M.Y.; Na,D. S.;Moon,H.B.; Pai,C.H. (1993). Detection of Salmonella typhi in the blood of Patients with typhoid fever by polymerase chain reaction. J. Clin. Microbiol.31,1439-1443.

17. Arora, D. R. and Arora, B. (2011). A text book of Microbiology. 3rd Edition, CBS publishers PV Ltd, New Delhi, India. Pp 352, 368-373, 376, 382, 385, 410-412.

18. Raveendran, R., Datta, S. and Chand, W. (2010). Drug Resistance in Salmonella enterica serotype typhi and para typhi A. IJMSA,23: 21-24. 